\title{
Astronomischer Jahresbericht
}

Gegründet von Walter F. Wislicenus

Mit Unterstïtzung der Astronomischen Gesellschaft

\author{
herausgegeben vom \\ Astronomischen Rechen-Institut
}

$z u$ Heidelberg

\author{
46. Band \\ Die Literatur der Jahre 1943-1946 \\ 2. Teil
}

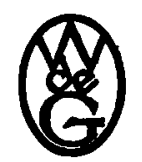

In Kommission bei

Walter de Gruyter \& Co.

vormals G. J. Göschen'sche Verlagshandlung - J. Guttentag, Verlaggbuchhandlung - Georg Reimer - Karl J. Trübner - Veit \& Comp. Berlin 1951 
Alle Rechte vorbehalten

Archiv-Nr. 180151

Veroffentlicht unter Zulassung Nr. CBIB der Nachrichtenkontrolle der Militarregierung

Gedruckt mit Unterstützung der Notgemeinschaft der Deutschen Wissenschaft

Druck: G. Braun (vorm. G. Braunsche Hofbuchdruckerei und Verlag) G.m.b.H., Karlsruhe in Baden

Printed in Germany

Auflage 500 - Juli 1951 